\title{
Genetic diversity among commercial coffee varieties, advanced selections and museum collections in Kenya using molecular markers
}

\author{
Kathurima C. W. ${ }^{1 *}$, Kenji G. M. ${ }^{2}$, Muhoho S. M. ${ }^{2}$, Boulanger R. ${ }^{3}$, Gichimu B. M. ${ }^{1}$ \\ and Gichuru E. K. ${ }^{1}$ \\ ${ }^{1}$ Coffee Research Foundation, P. O. Box 4 - 00232, Ruiru, Kenya. \\ ${ }^{2}$ Jomo Kenyatta University of Agriculture and Technology, P. O. Box 62000 - 00200, Nairobi, Kenya. \\ ${ }^{3}$ UMR QUALISUD TA B 95/16 73, Rue JF Breton 34398 Montpellier Cedex 5, France.
}

Accepted 20 December, 2011

\begin{abstract}
Molecular markers have effectively been applied to study genetic diversity and as markers of particular traits. This study assessed the diversity of twenty four (24) coffee genotypes using 10 Random Amplified Polymorphic DNA (RAPD) primers and 2 microsatellites (M24 and Sat 235). A total of 35 polymorphic bands were generated by the RAPD primers. The bands were scored for presence (1) and absence (0) of amplified products. The data was subjected to cluster analysis using $R$ statistical software and a dendrogram constructed using Unweighted Pair Group Method with Arithmetic Average (UPGMA). The genotypes separated into three main clusters. $C$. eugenioides clustered alone in the first cluster while un-introgressed Arabica genotypes dominated the second cluster. The third cluster comprised of Coffea canephora (Robusta) and introgressed genotypes, Ruiru 11, Hibrido de Timor and Catimor. Robusta and $C$. eugenioides were the most distantly related and generated most of the diversity observed. The similarities observed among un-introgressed Arabica genotypes attest to the narrow genetic diversity within Coffea arabica. The divergence observed among introgressed genotypes could be utilized in future breeding programmes.
\end{abstract}

Key words: Coffee accessions, RAPD, microsatellites, diversity, Kenya.

\section{INTRODUCTION}

Coffee belongs to the genus Coffea sub-genus Coffea, family Rubiaceae and is mostly present in tropical and subtropical regions of the world (Davis et al., 2006). The species which are most cultivated world-wide are Coffea arabica (Arabica coffee) and Coffea canephora (Robusta coffee). C. arabica is the only tetraploid species in the genus and is self-fertile, while other species are diploid and generally self-incompatible (Clarindo and Carvalho, 2008). French Missionaries introduced coffee into Kenya around 1900 AD (Mwangi, 1983). In Kenya, the commercial varieties recommended for cultivation include K7, SL 28 and SL 34. However, they are susceptible to

${ }^{\star}$ Corresponding author. E-mail: cwkathurima@yahoo.com. Tel: +254 20 2027190/2029384. Fax: +254202044923. diseases such as Coffee Berry Disease (CBD), Coffee Leaf Rust (CLR) and Bacterial Blight of Coffee (BBC). In view of the constraint to economic coffee production, development and cultivation of disease resistant varieties is a desirable effective and viable option.

The coffee trees conserved ex-situ at Coffee Research Station (CRS) Ruiru in germplasm field plots has many $C$. arabica accessions from Ethiopia, Sudan, Kenya, Tanzania, Angola, India, Reunion, Portugal, South and Central America (Kathurima et al., 2009). In spite of its significance, this Coffea collection has not been evaluated for genetic variability mainly at DNA level. Some of these conserved genotypes have been used as progenitors in a main breeding program at CRS (Walyaro, 1983).

The coffee breeding programme successfully transferred resistance to CLR and Coffee Berry Disease 
CBD from $C$. canephora, via the interspecific hybrid referred to as Hibrido de Timor (HDT, Timor Hybrid) (C. arabica x C. canephora) (Nyoro and Sprey, 1986). The cultivar developed from this breeding regime (Ruiru11) is suitable for all coffee growing areas because it is resistant to CBD and CLR (Opile and Agwanda, 1993). Recently, five coffee lines coded Cr8, Cr22, Cr23, Cr27 and Cr30 have been under evaluation at CRF with the prospect of releasing them as commercial varieties. The recently released variety, Batian, is a selection of these lines. Their unique features include tall stature, true breeding and resistance to both CBD and CLR (Gichimu and Omondi, 2010a).

According to Jump et al. (2008) there is heavy reliance on plant genetic diversity for future crop security in agriculture and industry. However, they observed that genetic diversity for natural populations receives less attention. Like it is for many crops, evaluation of the genetic diversity and available resources within the genus Coffea is an important step in coffee breeding (Cubry et al., 2008). As new coffee varieties are continuously being developed through hybridization, there is a need to determine the level and sources of genetic variation within and between new and existing coffee varieties (Gichimu and Omondi, 2010a). Genetic consistency within varieties is also essential to quality assurance for any agricultural product. Hue (2005) reported that morphological variability in coffee plantations is adverse to the product quality. Reduced genetic diversity is also reported to compromise the ability of populations to evolve to cope with environmental changes and thus reducing their chances of long-term persistence (Frankham et al., 2002). Determination of genetic diversity/consistency is therefore important not only in coffee but also to other crops. A variety of techniques have been utilized to measure genetic variation of coffee species. For instance, Walyaro (1983) successfully determined the diversity of eleven coffee genotypes using morphological characteristics. Gichimu and Omondi (2010b) also determined the morphological diversity among some newly developed and existing commercial cultivars in Kenya. However, morphological markers are reportedly inefficient because they are generally dominant traits, they often exhibit epistatic interactions with other genetic traits and can also be influenced by the environment (Weising et al., 2005).

Lashermes et al. (1996a) reported that genetic factors are more accurately tested by molecular markers. In the recent past, detection of genetic variation at DNA level has been made possible by the advent of molecular markers. Several DNA analysis techniques have been used to assess genetic diversity of coffee. The techniques differ in technical requirements, cost, sequence specificity and repeatability. RAPD, Restriction Fragment Length Polymorphism (RFLP) and Amplified Fragment Length Polymorphism (AFLP) do not require prior genetic sequence analysis for primer design and offer genome wide scanning. On the other hand, Microsatellites (Simple Sequence Repeat- SSRs) and Sequence characterised Amplified Regions (SCARs) are based on sequence specific primers with limited transferability across species but are more repeatable. In this study, RAPD were the main ones used due to their ease of use and availability of primers. In addition, SSRs that have been applied in our laboratory in the past were used. RAPD markers have been used extensively to study the genetic diversity and relationships among Coffea species (Lashermes et al., 1996a; Masumbuko et al., 2003; Aga et al., 2003; Tshilenge et al., 2009, Mishra et al., 2011). Microsatellites have also been applied in coffee to identify $C$. arabica, $C$. canephora and related species (Combes et al., 2000). They have also been used to investigate polymorphisms among wild and cultivated C. arabica accessions (Rovelli et al., 2000; Anthony et al., 2002; Baruah et al., 2003; Moncada and Couch 2004) and to analyze the introgression of DNA fragments from $C$. canephora and $C$. liberica into $C$. arabica (Lashermes et al., 2000, Lashermes, et al., 2010; Prakash et al., 2002; Gichuru et al., 2008). In Kenya, Agwanda et al., (1997) identified RAPD markers associated with CBD resistance which could be used to select against the genetic background of CBD resistance donors. Introgressed $C$. canephora fragments were identified in lines of HDT and cv Catimor and subsequently characterised as markers or candidate markers for disease resistance (Gichuru 2007; Gichuru et al., 2008). These genotypes are used as donors of resistance to CBD and CLR in Kenya. Omondi et al. (2009) reported SSR polymorphism between a disease resistance donor, Rume Sudan, and a susceptible cultivar, SL28. Most of the studies conducted focused on disease resistance. However, this study utilized RAPD and microsatellites to assess overall genetic diversity of museum genotypes, commercial varieties and upcoming coffee varieties in Kenya.

\section{MATERIALS AND METHODS}

\section{Plant materials}

Twenty four coffee genotypes comprising of one breeder's materials Catimor (Line 90), four commercial varieties, five advanced coffee selections and fourteen non-commercial accessions were used in this study (Table 1). The coffee trees of these genotypes are available in the commercial fields, experimental sites and museum plots at Coffee Research Station (CRS), Kenya.

\section{Genomic DNA extraction}

Disease-free leaves were picked from second and third nodes from the growing tips of the coffee branches for DNA extraction. Genomic DNA was extracted from the fresh leaf material by the method of Diniz et al. (2005) with minor modifications using mixed alkyltrimethylammonium bromide (MATAB). 
Table 1. Status and Sources of coffee germplasm used in the studies.

\begin{tabular}{clll}
\hline S/no. & Genotypes & Status & Source \\
\hline 1 & Marsabit & Museum accession & Wild from Northern Kenya \\
2 & Geisha 11 & Museum accession & Kitale, Kenya \\
3 & Columnaris & Museum accession & Puerto Rico \\
4 & Grafts & Museum accession & Not identified \\
5 & Moca & Museum accession & Yemen \\
6 & N39 & Museum accession & Lyamungu Tanzania \\
7 & C. eugenioides & Museum accession & Nandi Forest, Kenya \\
8 & Harar & Museum accession & Ethiopia \\
9 & Ennareta & Museum accession & Ethiopia \\
10 & Laurina & Museum accession & LA Reunion \\
11 & Hibrido De Timor & Museum accession & Portugal \\
12 & Pretoria & Museum accession & Guatemala \\
13 & K7 & Commercial variety & Kenya \\
14 & SL34 & Commercial variety & Kenya \\
15 & SL 28 & Commercial variety & Kenya \\
16 & Blue Mountain & Museum accession & Guatemala \\
17 & Robusta & Museum accession & Uganda \\
18 & Cross $8($ Cr 8) & Advanced Selection & Kenya \\
19 & Cross22 (Cr 22) & Advanced Selection & Kenya \\
20 & Cross 23 (Cr 23) & Advanced Selection & Kenya \\
21 & Cross30 Cr 30) & Advanced Selection & Kenya \\
22 & Cross 27 (Cr 27) & Advanced Selection & Kenya \\
23 & Catimor - Line 90 & Breeders' material & Colombia \\
24 & Ruiru11-Line 5 & Commercial variety & Kenya \\
\hline
\end{tabular}

\section{Amplification of coffee genomic DNA}

The method of Lashermes et al. (1996b) and modified by Agwanda et al. (1997) was used for RAPD analysis. Twenty one (21) arbitrary decamer oligonucleotides (Operon) were pre-selected and a subset showing clear amplifications were selected for analysis of the full set of study genotypes (Table 1). Amplification was carried out in a Eurogene thermocycler. The amplification program started with one cycle of initial denaturation at $94^{\circ} \mathrm{C}$ for 5 min followed by 45 cycles of $1 \mathrm{~min}$ at $94^{\circ} \mathrm{C}$ (denaturation), $1 \mathrm{~min}$ at $35^{\circ} \mathrm{C}$ (annealing), and 2 min at $72^{\circ} \mathrm{C}$ (elongation). The final extension was done at $72^{\circ} \mathrm{C}$ for $7 \mathrm{~min}$ to ensure that the primer extension reaction was completed. The RAPD products were electrophoresed in $1.8 \%(\mathrm{w} / \mathrm{w})$ agarose gel and then visualised in a UV trans-illuminator after staining in ethidium bromide solution. Two microsatellites were selected based on results by Gichuru (2007) and Omondi et al. (2009). The DNA was amplified using two micro-satellites primers, Sat 235 (with forward sequence of TCGTTCTGTCATTAAATCGTCAA and reverse sequence of GCAAATCATGAAAATAGTTGGTG) and M24 (with forward sequence of GGCTCGAGATATCTGTTTAG and reverse sequence of TTAATGGGCATAGGGTCC) by the methodology described by Combes et al. (2000) but visualized in $2.3 \%$ agarose gel.

\section{Band scoring and analysis}

The bands were scored for presence (1) and absence (0) in the various genotypes. The data was organized into a matrix and subjected to cluster analysis using $\mathrm{R}$ statistical software. A dendrogram was constructed using dissimilarity matrix calculation function and unweighted pair-group method using arithmetic averages (UPGMA) (Venables et al., 2006). The R command ' $g$ clus' was used to reorder the genotypes within a cluster keeping them contiguous to each other. The cluster dendrogram constructed was used to estimate the genetic diversity among the 24 genotypes indicating how closely related or different they were. These methods have been used in similar studies.

\section{RESULTS}

Among the twenty one (21) RAPD primers tested, 16 primers showed amplification out of which 14 produced clear bands that could be clearly scored (Plate 1). The total number of fragments observed among the coffee genotypes based on the 14 RAPD primers was 83 (Table 2). The number of bands produced per primer ranged from 2 to 12. Ten out of the 14 primers generated 35 polymorphic fragments. The other four primers did not show any polymorphism. Robusta and $C$. eugenioides gave rise to most of the diversity observed while the Arabica accessions variously shared bands with these two species. The two microsatellites tested also showed varying polymorphism amongst the genotypes (Plate 2). 


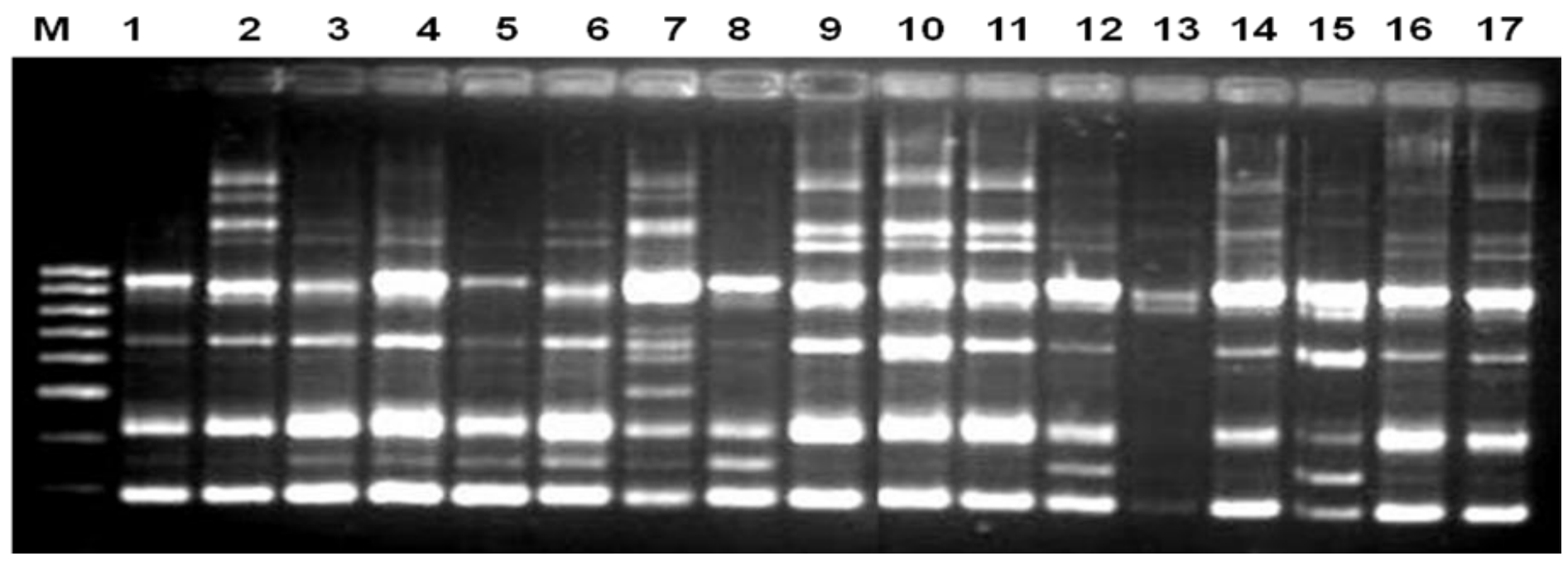

Plate 1. A panel of RAPD profiles generated by primer $\mathrm{Y}-10$ in coffee populations. $\mathrm{M}$ is a 100 base pair marker while lanes $1-17$ are coffee accessions.

Table 2. RAPD primers used for PCR analysis of 24 coffee accessions.

\begin{tabular}{clccc}
\hline S/no. & Primer & Total bands & Polymorphic bands & \% polymorphic \\
\hline 1 & OPI-07 - CAGCGACAAG & 12 & 10 & 83 \\
2 & OPJ-19 - TGAGCCTCAC & 9 & 4 & 44 \\
3 & OPK-03 - CCAGCTTAGG & 5 & 2 & 40 \\
4 & OPE-05 - TCAGGGAGGT & 4 & 1 & 25 \\
5 & OPE-08 - TCACCACGGT & 2 & 0 & 0 \\
6 & OPE-18 - GGACTGCAGA & 8 & 1 & 13 \\
7 & OPF-15 - CCAGTACTCC & 4 & 0 & 0 \\
8 & OPF-17 - AACCCGGGAA & 5 & 0 & 0 \\
9 & OPG-03 - GAGCCCTCCA & 4 & 4 & 100 \\
10 & OPG-05 - CTGAGACGGA & 4 & 1 & 25 \\
11 & OPN-18 - GGTGAGGTCA & 7 & 2 & 29 \\
12 & OPM-04 - GGCGGTTGTC & 4 & 0 & 0 \\
13 & OPX-20 - CCCAGCTAGA & 7 & 6 & 86 \\
14 & OPY-10 - CAAACGTGGG & 8 & 4 & 50 \\
& & 83 & 35 & 42 \\
\hline
\end{tabular}

$M$ is 100 base pair marker while 1 to 13 are coffee samples. The lower band (arrowed) is a marker for a Robusta genomic fragment present in HDT and its derivatives. A cluster dendrogram constructed using polymorphic bands was used to estimate the genetic diversity of the twenty four coffee accessions (Figure 1). The genotypes were separated into three main clusters. C. eugenioides clustered alone in the first cluster, Arabica accessions dominated the second cluster while the third cluster contained Robusta, Ruiru 11, Hibrido de Timor and Catimor. The R command ' $\mathrm{g}$ clus' which was used to reorder the genotypes within and among clusters and keeping them contiguous to each other depicted Robusta and $C$. eugenioides as the most distantly related. Except for $C$. eugenioides, the maximum dissimilarity index observed was 0.10 .

\section{DISCUSSION}

Molecular markers have been widely applied in studying the diversity of coffee. Use of different DNA technologies in such studies are expected to generate similar genetic relationships but have different degree of separation and 


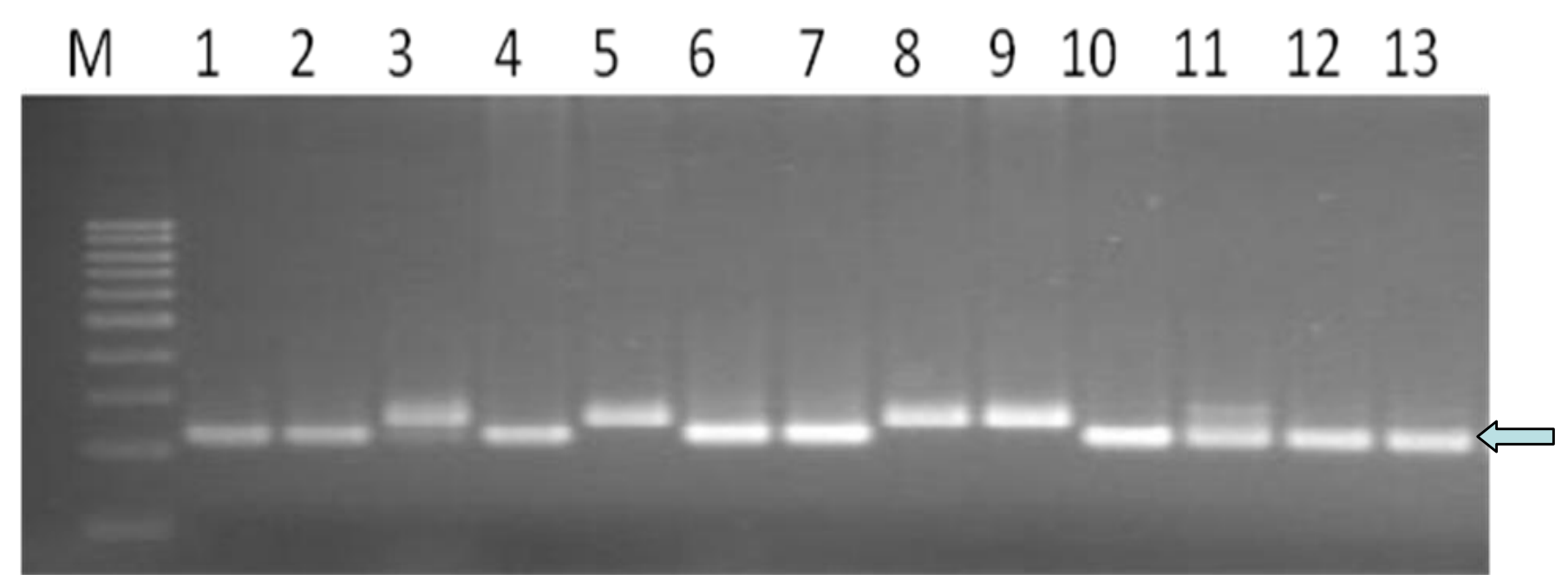

Plate 2. An example of a polymorphic band pattern generated by Sat 235 on the coffee genotypes.

reliability depending on the numbers of primers used and polymorphic bands generated. The results demonstrate that RAPD markers were able to reveal variability among the coffee accessions tested. This agrees with other researchers Lashermes et al. (1993); Agwanda et al. (1997); Anthony et al. (2001, 2002); Aga et al. (2003); Masumbuko et al. (2003) who reported the successful use of RAPD in genetic characterization in Coffea species. Although, Hibrido de Timor (HDT), Ruiru 11 and Catimor 90 clustered together with Robusta, it was apparent from the general analysis that the coffee accessions clustered according to the three different species namely Eugenioides, Robusta and Arabica. Thus, for rapid improvement in breeding work, widening of the existing genetic base through interspecific hybridisation is desirable. Similar observation was made by Lashermes et al. (1993) and Agwanda et al. (1997). A study of genetic diversity based on RAPD marker demonstrated high diversity in the spontaneous and subspontaneous hybridized materials of Ethiopia (Anthony et al., 2002).

Considering that the coffee genotypes evaluated in this study originated from diferent countries (Kenya, Puerto Rico, Tanzania, Ethiopia, Reunion, Portugal, Yemen, Guatemala and Colombia), the similarities observed among Arabica genotypes, attests to the narrow genetic diversity among cultivated Arabica coffee reported in other studies (Lashermes et al., 1993). Comparatively, higher genetic diversity has been reported among wild coffee populations than within cultivated genotypes (Anthony et al., 2000; Aga et al., 2003;Masumbuko et al., 2003; Masumbuko and Bryngelsson 2006; Maluf et al., 2005). Close genetic proximity was observed among the existing traditional commercial varieties in Kenya, namely SL28, SL34 and K7. These results are in agreement with the work of Agwanda et al. (1997) and Hue (2005) which revealed high genetic similarity between Kenyan traditional commercial varieties. In this study, the accession Marsabit which is a wild accession from Northern Kenya clustered with K7 which confirmed the findings of Lashermes et al. (1996b) that cultivar K7 was closely related to an accession collected in Marsabit Mountain.

Hibrido de Timor (HDT), Catimor Line 90 and Ruiru 11, were found to be genetically divergent from the rest of the varieties and bearing close relationship to Robusta coffee. Similar observations were made by Agwanda et al. (1997) and Lashermes et al. (1996b). Different lines of HDT have been used worldwide to breed coffee varieties that are resistant to different pathogens. As would be expected, different accessions of HDT derivatives have different levels of introgressed $C$. canephora genome (Lashermes et al., 2000; Silveira et al., 2003). This could explain the close relationship observed between HDT, Ruiru 11 and Catimor Line 90 to Robusta. On the other hand, the cultivar Ruiru 11 is a composite F1 hybrid between lines of the variety Catimor, (as the female parent), and male selections most of which have HDT in their pedigree. The breeding programmes to development the male parents involved backcrossing and selfing at various selection stages which affected the amount of Robusta genome passed on to the next generation. This can explain the wide range of diversity observed between HDT and its derivatives (Catimor Line 90, Ruiru 11 line 5, Cr8, Cr22, Cr23, Cr27 and Cr30).

The objective of this study was to widen the information on genetic diversity of coffee germplasm available for breeding programmes in Kenya since previous work was biased to commercial cultivars and donors of resistance to diseases. The study confirms the low genetic diversity in the Arabica coffee genotypes evaluated with dissimilarity of less than $5 \%$ (Figure 1). However, there is diversity that can be exploited in breeding programmes (Plates 3 and 4 ) and the possibility of identifying DNA 


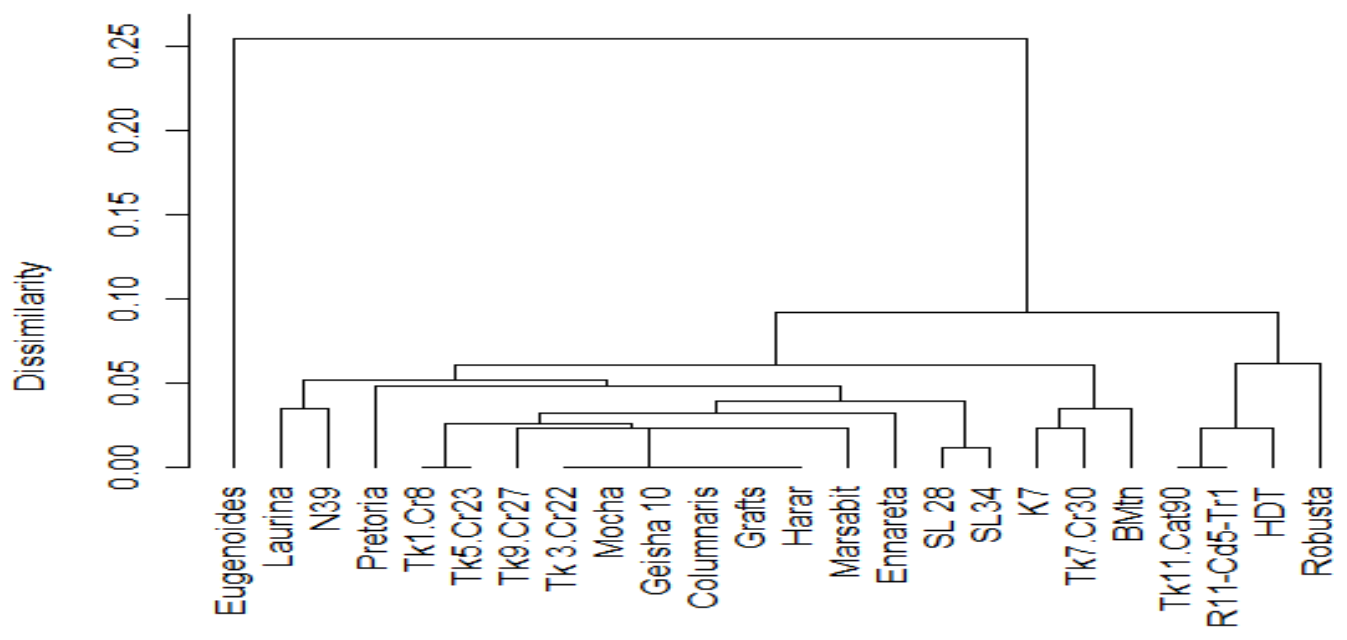

Figure 1. Cluster dendrogram illustrating genetic diversity among twenty four coffee genotypes.
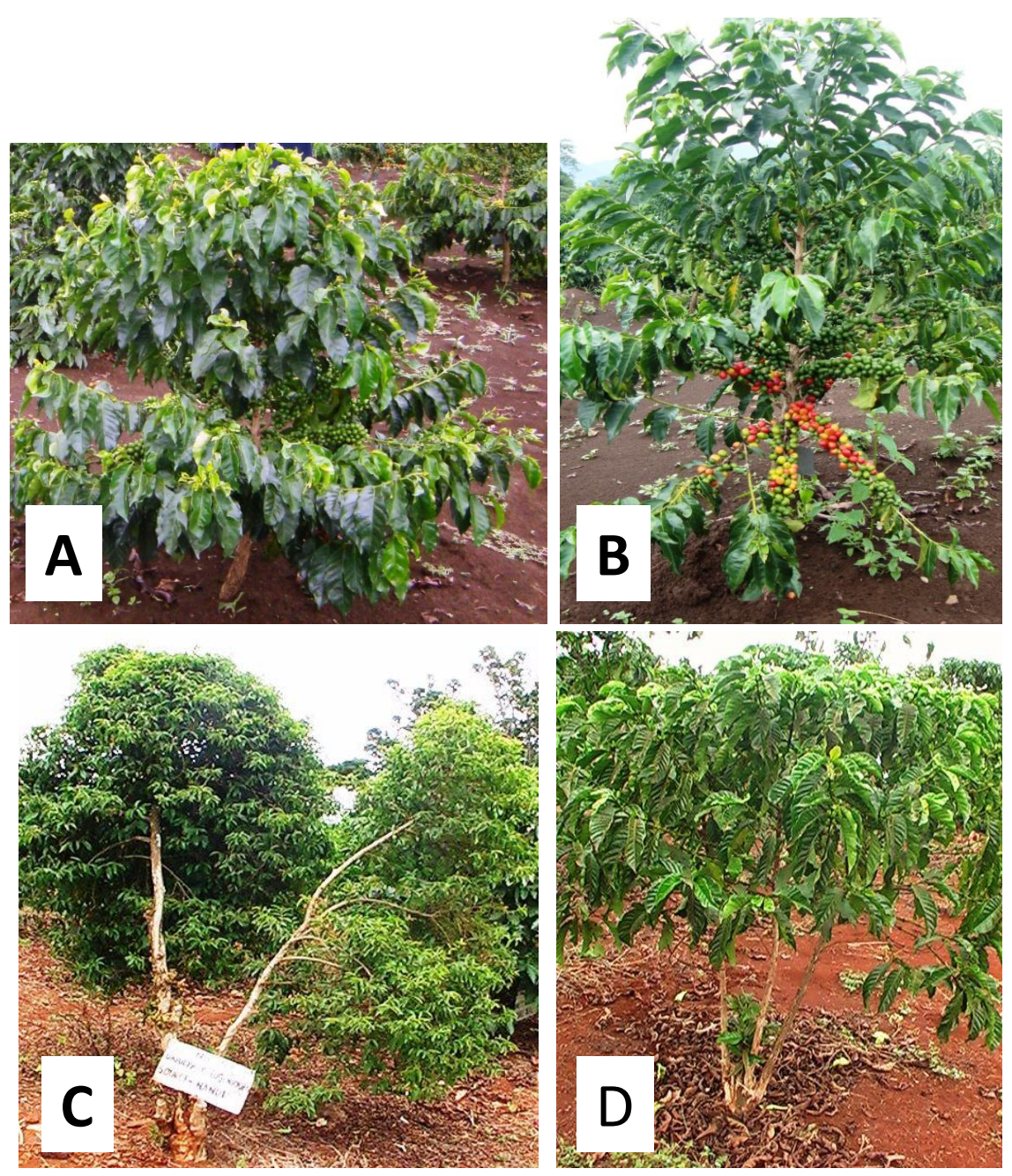

Plate 3. Differences in the canopies of various coffee varieties and species; $(A)$ the compact Ruiru II, (B) the tall advanced selection, (C) the bushy $C$. eugenioides, (D) the robust $C$. canephora. 

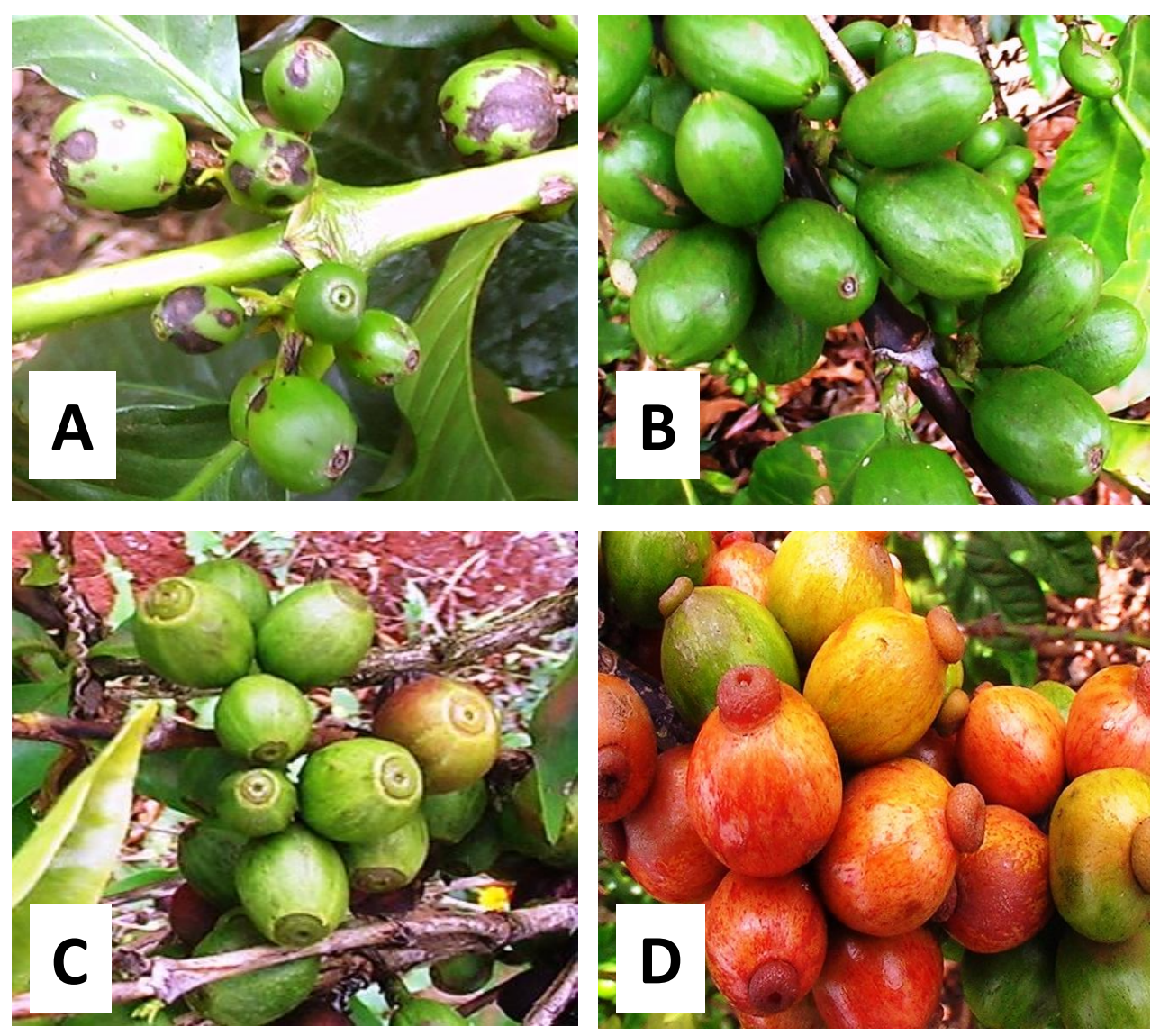

Plate 4. Differences in the berries of various coffee varieties and species; (A) SL 34 showing infection by Coffee Berry Disease, (B) Hibrido de Timor, (C) C. eugenioides, (D) C. canephora.

markers was demonstrated. It needs to be noted that the material analysed in this study represent a fraction of germplasm conserved in CRS museum plots and breeding materials. Previous breeding has focussed on the introduction of pest resistance into cultivated varieties. In fact the Sat 235 used in this study is linked to a gene of resistance to CBD (Gichuru et al., 2008). Future studies need to explore more germplasm and also attempt to relate the observed diversity to other traits with an objective of identifying parents for various breeding programmes. The traits can range from agronomic and quality related traits (such as caffeine content) to novel utilization of coffee such aesthetics. The divergence of HDT derivatives is also of importance in breeding programmes. For example, Ruiru 11 progenies comprise of 60 lines (Omondi et al., 2001) and therefore more intensive molecular analysis could help in characterizing them and consequently selecting elite lines.

\section{Conclusion}

Generally, the study confirmed the narrow genetic base reported in $C$. arabica and emphasized the need to widen the existing genetic diversity through interspecific hybridisation. Although, RAPD markers were able to determine variability among the coffee accessions tested, combination of multiple molecular techniques (such as AFLP, RFLP, SSRs, and SCARs) may reveal more accurate estimation of genetic diversity and relate the diversity to qualitative traits in subsequent studies.

\section{ACKNOWLEDGEMENTS}

This work was facilitated by Coffee Research Foundation (CRF) in collaboration with European Union through Quality Coffee Production and Commercialization support Programme (QCPCP). The help rendered by the CRF Molecular laboratory staff during this study is highly appreciated. This work is published with the permission of the Director of Research, CRF, Kenya.

\section{REFERENCES}

Aga E, Bryngelsson T, Bekele E, Salomon B (2003). Genetic diversity of 
forest arabica coffee (Coffea arabica L.) in Ethiopia as revealed by random amplified polymorphic DNA (RAPD) analysis. Hereditas. 138: 36-46.

Agwanda CO, Lashermes $P$, Trouslot $P$, Combes MC, Charrier A (1997). Identification of RAPD markers for resistance to coffee berry disease, Colletotrichum kahawae, in Arabica coffee. Euphytica, 97: 241-248.

Anthony F, Astorga-Domian CG, Quiros O, Bertrand B, Etienne H, Topart P, Lashermes P (2000). Genetic diversity of wild and cultivated coffees (Coffea arabica) revealed by molecular markers. Proceedings of the 19th Latin American Symposium on Coffee, Oct. 2-6, Memory, San Jose, pp: 251-261.

Anthony F, Bertrand B, Quiros O, Wilches A, Lashermes P, Berthaud J, Charrier A (2001). Genetic diversity of wild coffee (Coffea arabica L.) using molecular markers. Euphytica. 118: 53-65.

Anthony F, Combes MC, Astorga C, Bertrand B, Graziosi G, Lashermes $P$ (2002). The origin of cultivated Coffea arabica $L$. varieties revealed by AFLP and SSR markers. Theor. Appl. Genet. 104: 894-900.

Baruah A, Naik V, Hendre PS, Rajkumar R, Rajendrakumar P, Aggarwal RK (2003). Isolation and characterization of nine microsatellite markers from Coffea arabica L. showing wide crossspecies amplifications. Mol. Ecol. Notes, 3: 647-650.

Clarindo WR, Carvalho CR (2008). First Coffea arabica karyogram showing that this species is a true allotetraploid. Plant Syst. Ev., 274: 237-241.

Combes MC, Andrzejewski S, Anthony F, Bertrand B, Rovelli P, Graziosi G Lashermes P (2000). Characterization of microsatellites loci in Coffea arabica and related coffee species. Mol. Ecol., 9: 11781190.

Cubry $P$, Musoli $P$, Legnate $H$, Pot $D$, de Bellis $F$, Poncet $V$, Anthony F, Dufour M, Leroy $T$ (2008). Diversity in coffee assessed with SSR markers: Structure of the genus Coffea and perspectives for breeding. Genome, 51: 50-63.

Davis AP, Governs R, Birdsong DM, Stoffelen P (2006). An annotated taxonomic onspectus of the genus Coffea L. (Rubiceae). Bot. J. Linn. Soc., 152: 465-512.

Diniz LFC, Ruas CF, Carvalho VP, Torres FM, Ruas EA (2005). Genetic Diversity Among Forty Coffee Varieties Assessed by RAPD Markers Associated with Restriction Digestion. Braz. Arch. Biol. Tech., 48(4): 511-521.

Frankham R, Briscoe DA, Ballou JD (2002). Introduction to Conservation Genetics. 4th Edn., Cambridge University Press, New York, USA.

Gichimu BM and Omondi CO (2010a). Early performance of five newly developed lines of Arabica coffee under varying environment and spacing in Kenya. Agric. Biol. J. North

Am., 1: 32-39.

Gichimu BM and Omondi CO (2010b). Morphological Characterization of Five Newly Developed Lines of Arabica coffee as Compared to Commercial Cultivars in Kenya. Int. J. Plant Breed. Gene., 4: 238246.

Gichuru EK, Agwanda CO Combes MC Mutitu EW, Ngugi ECK, Bertrand B, Lashermes P (2008). Identification of molecular markers linked to a gene conferring resistance to coffee berry disease Colletotrichum kahawae in Coffea arabica. Plant Pathol., 57: 11171124.

Gichuru EK (2007). Characterization of genetic resistance to Coffee Berry Disease (Colletotrichum kahawae Waller and Bridge) in Arabica coffee (Coffea arabica L.) that is introgressed from Coffea canephora Pierre. Ph.D. Thesis, University of Nairobi.

Hue TTM (2005). Genetic variation in cultivated coffee (Coffea arabica L.) accessions in Northern New South Wales, Australia. Master's Thesis, Southern Cross University.

Jump AS, Marchant R, Penuelas J (2008) Environmental change and the option value of genetic diversity. Trends Plant Sci., 14: 51-58.

Kathurima CW, Gichimu BM, Kenji GM, Muhoho SM, Boulanger R (2009). Evaluation of beverage quality and green bean physical characteristics of selected Arabica coffee genotypes in Kenya. Afr. J. Food Sci., 3: 365-371.

Lashermes P, Cros J, Marmey P, Charrier A (1993). Use of random amplified DNA markers to analyse genetic variability and relationships of Coffea species. Genet. Resour. Crop Evol., 40: 9199.

Lashermes P, Trouslot P, Anthony F, Combes MC, Charrier A (1996a). Genetic diversity for RAPD markers between cultivated and wild accessions of Coffea arabica. Euphytica, 87: 59-64.

Lashermes P, Cros J, Combes MC ,Trouslot P, Anthony F, Hamon S, Charrier A (1996b). Inheritance and restriction fragment length polymorphism of chloroplast DNA in the genus Coffea L. Tag Theor. Appl. Gene., 93: 626-632.

Lashermes P, Andrzejewski S, Bertrand B, Combes MC, Dusert S, Graziosi G, Trouslot P, Anthony F (2000). Molecular analysis of introgressive breeding in coffee (Coffea arabica L.). Theor. Appl. Gen., 100: 139-146.

Lashermes P, Combes MC, Ansaldi C, Gichuru EK, Noir S (2010). Analysis of alien introgression in coffee tree (Coffea arabica L.). Mol. Breed, 27: 223-232.

Maluf MP, Silvestrini M, Ruggiero LMC, Filho OG, Colombo CA (2005). Genetic diversity of cultivated Coffea arabica inbred lines assessed By RAPD, AFLP and SSR marker systems. Sci. Agric., 62: 366-373.

Masumbuko LI, Bryngelsson T, Mneney EE, Salomon B (2003). Genetic diversity in Tanzanian Arabica coffee using random amplified polymorphic DNA (RAPD) markers. Hereditas, 139: 56-63

Masumbuko LI, Bryngelsson T (2006). Inter simple sequence repeat (ISSR) analysis of diploid coffee species and cultivated Coffea arabica L. from Tanzania. Gen. Res. Crop Evol., 53: 357-366.

Mishra MK, Nishani S, Jayarama (2011). Genetic relationship among indigenous coffee species from India using RAPD, ISSR and SRAP markers. Biharean Biologist, 5: 17-24.

Moncada P, McCouch S (2004). Simple sequence repeats diversity in diploid and tetraploid Coffea species. Genome, 47: 501-509.

Mwangi CN (1983). Coffee Growers' Handbook. Coffee Research Foundation, Kenya.

Nyoro JK, Sprey LH (1986). Introducing Ruiru 11 to the estates and small holders. Kenya Coffee, 51: 4-28.

Omondi CO, Ayiecho PO, Mwang'ombe AW, Hindorf H (2001) Resistance of Coffea arabica cv. Ruiru 11 tested with different isolates of Colletotrichum kahawae, the causal agent of coffee berry disease. Euphytica, 121:19-24

Omondi CO, Gichuru EK, Combes MC, Lashermes P (2009). SSR polymorphism in breeding populations of Arabica Coffee with varying reactions to coffee berry disease. Plant and Animal Genomes XVII Conference January 10-14, San Diego, CA, USA.

Opile WR, Agwanda CO (1993). Propagation and distribution of cultivar Ruiru 11: A review, Kenya Coffee, 58: 1496-1508.

Prakash NS, Combes MC, Somanna N, Lashermes P (2002). AFLP analysis of introgression in coffee cultivars (Coffea arabica L.) derived from a natural interspecific hybrid. Euphytica, 124: 265-271.

Rovelli P, Mettulio R, Anthony F (2000). Microsatellites in Coffea arabica L. In: Coffee Biotechnology and Quality, Sera et al. (Eds.), Kluwer Academic Publishers, Amsterdam, Netherlands.

Silveira SR, Ruas PM, Ruas CF, Sera T, Carvalho VP, Coelho ASG (2003). Assessment of genetic variability within and among coffee progenies and cultivars using RAPD markers. Genet. Mol. Biol., 26: 329-336.

Tshilenge P, Nkongolo KK, Mehes M, Kalonji A (2009). Genetic variation in Coffea canephora L. (Var. Robusta) accessions from the founder gene pool evaluated with ISSR and RAPD. Afr. J. Biotechnol., 8: 380-390.

Venables WN, Smith DM, R Development Core Team (2006). An introduction to R: A programming environment for data analysis and graphics. Version 2.5.1.

Walyaro DJA (1983). Considerations in breeding for improved yield and quality in Arabica coffee (Coffea arabica L.). Ph.D. Thesis, Wageningen Agricultural University.

Weising $\mathrm{K}$, Nybom $\mathrm{H}$, Wolff $\mathrm{K}$ Kahl $\mathrm{G}$ (2005). DNA Fingerprinting in Plants. Taylor and Francis Group, United Kingdom. 